\title{
Recognition of Factors Related to Low Back Pain Promotes Behavior Change among Female Nurses
}

\author{
Keiko Takeda ${ }^{1}$ and Yoriko Watanabe ${ }^{2}$ \\ 1. Faculty of Health Sciences, Nihon Fukushi University, Aichi 475-0012, Japan \\ 2. School of Nursing, University of Shizuoka, Shizuoka 422-8021, Japan
}

\begin{abstract}
We examined the relationships between recognition of the physical and psychosocial factors related to low back pain (LBP) and behavioral change among female nurses with LBP. Our specific purpose was to determine whether a program aimed at improving recognition of the factors associated with LBP was effective in enacting behavioral change and thereby improving LBP. The LBP-recognition group, compared to the non-recognition group, showed significant increases in scores on the "deep adjustment" factor of the Emotional Labor Inventory for Nurses and the "changing a point of view" factor of the Brief Scales for Coping Profile. The former group also exhibited a significant improvement in LBP. Thus, promoting recognition of the physical and psychosocial factors of LBP among female nurses can lead to behavioral changes.
\end{abstract}

Key words: Female nurses, low back pain (LBP), LBP recognition, behavioral change.

\section{Introduction}

Low back pain (LBP) is highly prevalent in Japan, being the most common disorder among men and the second most common among women [1]. In 2011, the total annual medical costs for work-related LBP exceeded \$724,885,500 (approx. 82 billion yen), and they have been steadily increasing since 2002 [2]. The severity of LBP is associated not only with worsening health status but also with increased medical costs [3].

In Japan, the prevalence of LBP among nurses ranges from $52.6 \%$ to $91.9 \%$ [4-8], and it is greater than that among other occupations such as physical therapists $[8,9]$. This rate has not shown any signs of improvement. Most explanations for LBP have been based on a biomedical model. This has led to a deep-seated perception of LBP as being caused by physical factors such as poor posture (e.g., bending forward). The predominance of this model has led most efforts aimed at preventing LBP among nurses to focus on the use of body mechanics [10,11], such as physical support. However, in $85 \%$ of LBP cases, the causes are

Corresponding author: Keiko Takeda, R.N., Ph.D., research field: nursing science. indeterminate and nonspecific.

The notion that physical posture is the main cause of LBP (based on the biomedical model) has begun to be replaced by the understanding that LBP is primarily a biopsychosocial pain syndrome. Indeed, twenty years ago, the UK (1996) conceptualized lumbago as a biopsychosocial pain syndrome [12], while in Japan, the 2012 Guidelines for the Diagnosis and Treatment of Low Back Pain [13] have proposed that "prolonged involvement of psychosocial factors contributes to the development of low back pain." However, while nursing education on LBP prevention includes training in body mechanics, gaps in the curriculum have prevented widespread recognition that psychosocial factors can also underlie its development. Effective educational programs for people with LBP include acupuncture treatment [14] and the CORE exercise program [15]. Furthermore, programs that seek to promote health knowledge and improve habits can avert development of LBP, provided that the program combines movement practice with the requisite knowledge to motivate students rather than merely transmitting information [16]. 
In 2013, Japan's Ministry of Health, Labour and Welfare revised its 19-year-old guidelines for preventing LBP, and began encouraging businesses to adopt organizational strategies that address employee LBP, such as manager and colleague support or counseling services [17]. The guidelines indicate that LBP must be understood holistically, which would include knowledge of its psychosocial factors (e.g., stress). Such factors are particularly relevant to nursing, which, as a helping profession, demands that nurses control their emotions and act according to certain emotional rules [18]. This emotional labor is defined by Hochschild as the expression or repression of emotions to maintain an outward appearance that will lead others to feel that they are being cared for in a place that is not only convivial and caring, but also safe [19]. To promote nurses' recognition of the physical and psychosocial factors related to LBP, we designed a self-improvement program called the "Education Program." This program aims to improve recognition of these factors and thereby facilitate behavioral change. The purpose of the present study was to determine whether this program improved recognition of the factors related to LBP and whether this improved recognition led to behavior changes among nurses. We considered LBP to be any condition in which a person feels pain in her lower back area.

\section{Materials and Methods}

\subsection{Program Development}

The 2012 Guidelines for the Diagnosis and Treatment of Low Back Pain state that cognitive behavioral therapy (CBT) is useful for the treatment of both acute and chronic LBP. According to the Hierarchal Cognitive Model of CBT, moods or feelings, physical reactions, and behaviors are reflections of individuals' "recognitions" of environmental stressors. These four domains are interrelated, which suggests that there is a cyclical interrelationship between individuals and their environments [20]. Thus, among nurses, LBP may be considered a physical reaction arising from the effects of work and other stressors.

People typically respond to events in the environment with automatic thoughts, which then effortlessly and instantaneously rise into consciousness at the point of recognition. Such automatic thinking, including imagination, arises from schemas, which are deep-seated beliefs and perspectives about the world. Schemas do not easily rise into consciousness, although they regularly influence cognition.

Given that LBP is considered a biopsychosocial pain syndrome, it is likely to be affected by automatic thinking as well. LBP is a physical reaction that it is difficult to directly control; on the other hand, recognition and behavior can be intentionally managed. Recognition and behavior, however, can be intentionally managed. Because recognition is influenced by the environment and can influence behavior and emotions, judicious use of recognition can help facilitate behavioral modification to improve LBP. Thus, the Hierarchal Cognitive Model provided the basis for the development of our program.

As part of program development, we conducted three surveys on nurses' recognition of the relationship between psychosocial factors and LBP among nurses and on the relationship between burden on the lower back and frontal-lobe-related cognitive functions. The first was an interview survey, which revealed that although nurses with LBP learned techniques for postural improvement in order to avoid burdening the lower back, they were still heavily burdened, both physically and psychosocially, by their tendency to prioritize others and their own work over self-care. The study also showed that nurses without LBP tended to have high psychosocial recognition and employed appropriate coping methods to avoid developing LBP [21]. The second survey was a questionnaire survey of 141 female nurses. Although LBP and psychosocial factors were determined to be related, nurses had a relatively low level of recognition of that relationship [22]. Finally, the third survey showed that lower back burden when a person assists with a wheelchair transfer 
is related to a twisting motion in the lower back, psychological burden such as stress, and cognitive functions related to deciding how to execute the assisting action [23]. In that study, we proposed that to alleviate lower back burden, recognition among nurses must be fostered on the necessity of attending to their own physical and psychosocial circumstances when providing assistance, and to cognitively evaluate and adjust.

From these results, we designed a draft program with two modules: a knowledge module and a practice module (which comprised physical posture techniques and psychosocial practice). In the knowledge module, sources such as the 2012 Guidelines for the Diagnosis and Treatment of Low Back Pain were used to explain how LBP, as a biopsychosocial pain syndrome, relates to various physical and psychosocial factors. For the practice module, we used exercises suggested by Watarai [24], who indicated that in order to move the body well, individuals must be aware of their posture and integrate knowledge, movement, and feeling; this approach is referred to as "Anatomy, Alignment, and Recognition." For the psychosocial practice, we focused on helping participants understand the underlying causes of stress and thereby relieve them. This approach was based on the fact that chronic LBP in adults is a response to stress, and improvement and prevention of LBP can be expected if appropriate coping strategies are used to manage the stresses of daily life [25].

A preliminary survey using the draft program highlighted how the program needed a more concrete methodology for relieving stress. Thus, we incorporated a CBT column technique into the program. This technique can be used to restructure cognition by replacing negative thoughts with positive ones. More specifically, when something has gone wrong in life, this technique is used to facilitate the individual's ability to think rationally in order to overcome negative automatic thoughts and overcome their difficulties [26]. We designed a four-column template for the program; the columns were labeled "Event," "Mood," "Way of thinking," and "Think positively!"

The table of contents for the program was as follows:

(1) Knowledge Module (Step 1, Learning about LBP): a. "LBP is not just pain in your lower back"; $b$. "Nurses and LBP"; c. "Understanding LBP as a biopsychosocial pain syndrome"; d. "Having a lot of stress is a psychosocial factor related to LBP."

(2) Practice Module (Step 2, Approaches to preventing and improving LBP): a. "Relaxing the spine"; b. "Maintaining good alignment"; c. "Recognizing both physical and psychosocial factors"; d. "Thinking positively"; e. "Changing your mood."

In the knowledge module, nurses learn to appreciate that LBP is a biopsychosocial pain syndrome and to recognize its relationship with various physical and psychosocial factors. Once nurses have learned to recognize LBP and its related factors, they are able to appropriately modify their behavior through practice, with the aim of improving their LBP. We also presented them with the experiences of nurses with LBP obtained from essential research on the topic, for participants who had an interest.

\subsection{Design}

We designed this study to test whether the program was effective in leading to a behavioral change and improving LBP. The primary outcome measure was LBP measured on a visual analog scale (VAS), and a secondary outcome measure was whether nurses had learned to recognize the physical and psychosocial factors. This latter condition was considered necessary for behavior modification to improve LBP (Fig. 1).

\subsection{Participants}

We limited potential participants to female graduates of 4-year university nursing programs in order to avoid introducing confounds. Further, candidates had to be in their first year of employment after graduation, when LBP prevalence is highest, or in their fifth year after graduation, because that is the median of nursing 


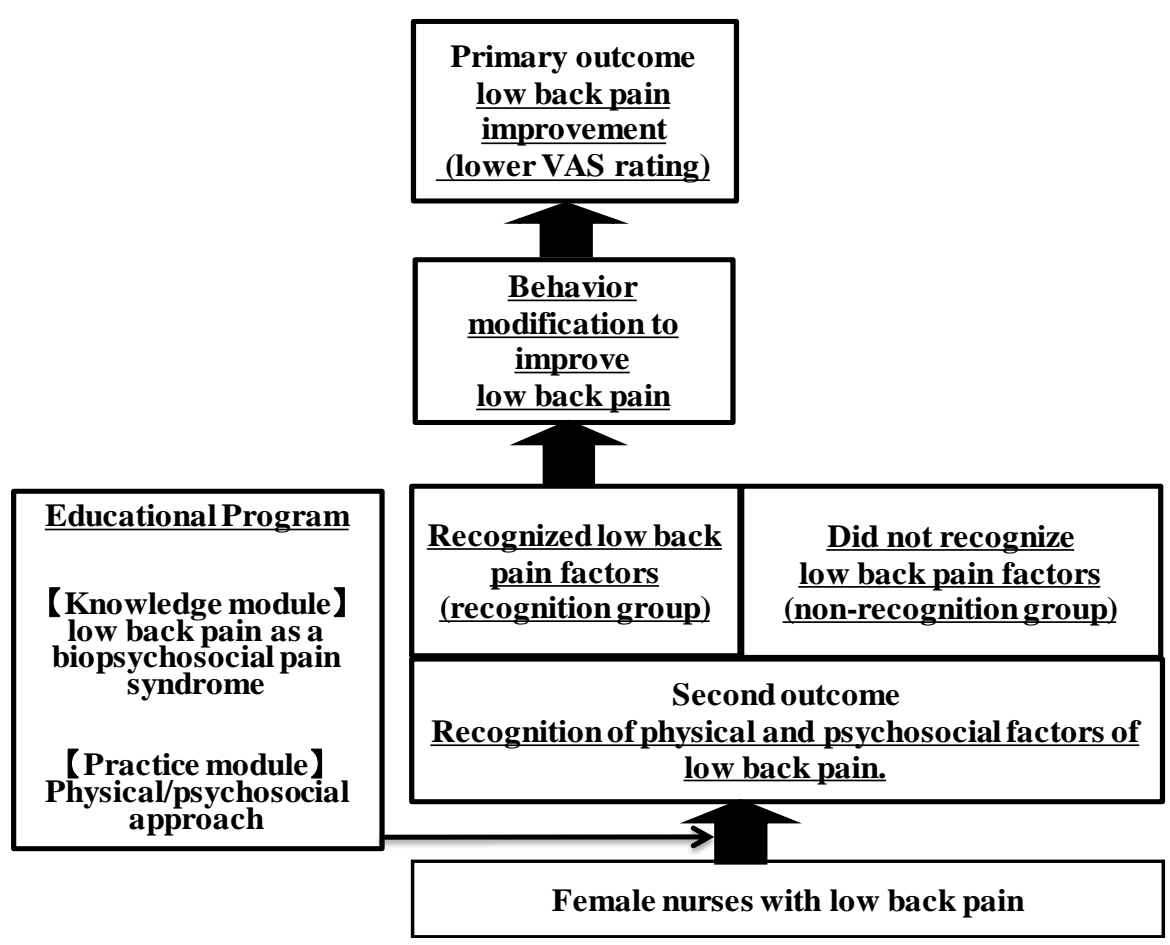

Fig. 1 Conceptual framework of the study.

experience groups for which the employment rate is high.

Ultimately, participants were 286 female nurses working at 17 hospitals with 500-1,400 beds and that had been founded by different organizational entities. All participants were in either their first or fifth year of employment after graduating from a 4-year nursing university. Participants were excluded if they were receiving treatment for a medically diagnosed condition. All of them had good physical and mental well-being.

\subsection{Survey Items}

\subsubsection{Recognition (Physical and Psychosocial Factor} Recognition)

A field was provided for the subject to indicate with a " $\bigcirc$ " (the Japanese equivalent of $\checkmark$ ) all of the physical and psychosocial factors that they recognized as being related to their LBP, based on an understanding that LBP is a biopsychosocial pain syndrome.

2.4.2 Behavior (Body Mechanics, Emotional Labor Inventory for Nurses)

We measured participants' use of 10 body mechanics techniques from the basic nursing skills curriculum [27] using a 4-point scale: 1 = always keep in mind and use, 2 = sometimes use, $3=$ almost never use, and $4=$ never use.

To measure emotional labor, we used the Emotional Labor Inventory for Nurses [28]. This inventory has five subscales, namely, "exploratory understanding," "surface adjustment," "suppressed expression," "expression of caring," and "deep adjustment." All were measured on a 5 -point scale: $1=$ don't do, $2=$ rarely do, $3=$ sometimes do, and $4=$ frequently do, $5=$ always do.

\subsubsection{Psychological Reactions (Stress Response)}

To measure workplace-related stress and job stressors, we used the Brief Job Stress Questionnaire [29]. The Stress Response subscale comprises two items (positive and negative psychological response).

2.4.4 Physical Reactions (LBP and Physical Stress Response)

LBP was measured on a VAS. The VAS was a 100-mm straight line with "No pain" on the extreme left and "Pain interferes with work" on the extreme right. We measured physical stress response as using the Brief Job Stress Questionnaire, described above. 


\subsubsection{Environment (Job Stressors)}

To measure stressors, we used the Job Stressor subscale of the Brief Job Stress Questionnaire, which comprises nine items (quantitative psychological overload, qualitative psychological overload, physical overload, job control, care skills use, interpersonal relations, work environment, job fitness, and job motivation).

\subsubsection{Coping (Brief Scales for Coping Profile)}

To assess coping strategies for dealing with worries and problems, we confirmed the validity of the Brief Scales for Coping Profiles version 3 [30] among nurses. This scale comprises six subscales corresponding to various coping strategies: "changing mood," "active solution," "taking out emotions to others," "seeking help for solution," "changing a point of view," and "avoidance and suppression." As an additional measure, we created a CBT column template for use in cognitive restructuring, which was described previously.

\subsection{Data Collection}

After obtaining their informed consent, we provided an explanation of the program's content. Participants were asked to read the knowledge module and to do as much of the practice module as they felt comfortable doing. We explained that they should stop immediately if they felt that their LBP was worsening or if their back was becoming strained. The program took 2 weeks to complete. Before and after the program, the participants completed the self-administered questionnaire (comprising the measures above) and the CBT column template. The study duration was from May through October 2012.

\subsection{Data Analysis}

We determined the percentages of factors that participants recognized as being related to LBP. Further, to confirm whether participants modified their behavior, we compared mean scores for the above measures between in the LBP items for each variable, the pre- and post-program differences between the groups were analyzed using the Wilcoxon test. Additionally, a Spearman's rank-correlation coefficient analysis to confirm the relationships between recognition of factors and the various other measures. SPSS Statistics 22.0 for Windows was used for statistical analysis, and statistical significance was set at $P<0.05$. Pre- and post-program results for "Think positively!" in the column templates were categorized by the co-authors and compared.

\subsection{Ethical Considerations}

This study was approved by the XXX internal review board (approval \# 12002). All participants provided their written informed consent prior to participation.

\section{Results}

Of the 286 nurses who were asked to participate, 60 (valid response rate: $21 \%$ ) gave their informed consent and were able to complete the pre- and post-surveys. Thirty-one $(51.7 \%)$ were in their first year of employment after graduation and $29(48.3 \%)$ were in their fifth year.

While the number of participants who indicated recognition of the physical factors before the program was high ( $n=59,98.3 \%)$, few nurses recognized both the physical and psychosocial factors $(n=15,25 \%)$. This significantly increased to $30(50.0 \%)$ after the $\operatorname{program}(Z=-2.934, P=0.003)$. Accordingly, these 30 participants were assigned to the "recognition" and "non-recognition" groups.

\subsection{Pre-/Post-Program Comparisons of the Recognition and Non-recognition Groups}

We examined the pre- and post-program differences in both groups to confirm how behavior changed after the program.

Notably, some of the post-program scores related to "behavior" significantly improved; for instance, the "use of body mechanics techniques" $(Z=-2.51, P=$ 
0.012) and "deep adjustment" both decreased significantly $(Z=-2.97, P=0.003$; Table 1$)$.

Post-program scores for the "negative psychological response" item of psychological reactions significantly decreased $(Z=-2.18, P=0.029)$. In addition, the post-program scores for the "coping" subscales of "changing a point of view" $(Z=-2.215, P=0.027)$ and "active solution" $(Z=-2.360, P=0.018)$ significantly decreased.

Organizing the "Think positively!" responses in the pre-program CBT column template for the recognition group resulted in the following categories, in decreasing

Table 1 Pre-/post-program comparisons in Recognition Group $(n=30)$.

\begin{tabular}{|c|c|c|c|c|c|c|}
\hline \multirow{3}{*}{ Item } & & & Pre-program & Post-program & \multirow{3}{*}{ Test value } & \multirow{3}{*}{ Cohen's 1} \\
\hline & & & \multirow{2}{*}{$\begin{array}{l}n(\%) \\
\text { Mean } \pm \text { SD }\end{array}$} & \multirow{2}{*}{$\begin{array}{l}n(\%) \\
\text { Mean } \pm \text { SD } \\
\end{array}$} & & \\
\hline & & & & & & \\
\hline \multicolumn{7}{|c|}{ Recognition } \\
\hline & \multirow{2}{*}{\multicolumn{2}{|c|}{$\begin{array}{l}\text { physical factor of low back pain } \\
\text { psychosocial factor of low back pain }\end{array}$}} & $30(100 \%)$ & $30(100 \%)$ & 0.000 & 0.0 \\
\hline & & & $15(50 \%)$ & $30(100 \%)$ & $-3.873 * * *$ & -0.48 \\
\hline \multicolumn{7}{|c|}{ Behavior } \\
\hline & \multicolumn{2}{|c|}{ Use of body mechanics techniques $\dagger$} & $24.6 \pm 4.31$ & $21.9 \pm 6.21$ & $-2.507 *$ & -0.46 \\
\hline & ERIN $\S$ & Exploratory understanding & $38.8 \pm 5.4$ & $37.4 \pm 6.6$ & -0.990 & -0.18 \\
\hline & \multirow{4}{*}{$\begin{array}{l}\text { ( Emotional Labor } \\
\text { Inventory for Nurses) }\end{array}$} & Surface adjustment & $14.0 \pm 4.2$ & $14.7 \pm 3.9$ & -1.187 & -0.22 \\
\hline & & Suppressed expression & $15.5 \pm 4.1$ & $16.2 \pm 4.4$ & -1.499 & -0.27 \\
\hline & & Expression of caring & $9.8 \pm 2.6$ & $10.1 \pm 2.6$ & -0.805 & -0.15 \\
\hline & & Deep adjustment & $8.5 \pm 3.1$ & $9.8 \pm 2.4$ & $-2.970 * *$ & -0.54 \\
\hline \multicolumn{7}{|c|}{ Mood/feelings } \\
\hline & \multirow{2}{*}{\multicolumn{2}{|c|}{$\begin{array}{ll}\text { Stress response } \$ \quad \begin{array}{l}\text { Positive psychological response } \\
\text { Negative psychological response }\end{array} \\
\end{array}$}} & $4.5 \pm 1.4$ & $4.7 \pm 1.2$ & -0.640 & -0.12 \\
\hline & & & $16.2 \pm 3.9$ & $17.5 \pm 3.8$ & $-2.183^{*}$ & -0.40 \\
\hline \multicolumn{7}{|c|}{ Physical reactions } \\
\hline & \multicolumn{2}{|l|}{$\begin{array}{l}\text { Low Back } \\
\text { Pain(VAS) }\end{array}$} & $30.8 \pm 22.4$ & $27.2 \pm 24.2$ & -0.184 & -0.25 \\
\hline & Stress response $t$ & Physical complaint & $28.5 \pm 6.8$ & $21.9 \pm 6.2$ & -0.773 & -0.14 \\
\hline \multicolumn{7}{|c|}{ Environment } \\
\hline & \multirow[t]{9}{*}{ Job stressors $t$} & Quantitative psychological overload & $5.2 \pm 1.7$ & $5.0 \pm 1.6$ & -0.911 & -0.17 \\
\hline & & Qualitative psychological overload & $5.1 \pm 1.7$ & $5.2 \pm 1.4$ & -0.587 & -0.11 \\
\hline & & Physical overload & $1.5 \pm 0.6$ & $1.6 \pm 0.6$ & -0.816 & -0.15 \\
\hline & & Job control & $7.7 \pm 1.7$ & $7.3 \pm 1.3$ & -1.799 & -0.33 \\
\hline & & Care skills use & $3.0 \pm 0.7$ & $2.9 \pm 0.6$ & -0.749 & -0.14 \\
\hline & & Interpersonal relations & $1.9 \pm 0.7$ & $1.8 \pm 0.6$ & -1.414 & -0.26 \\
\hline & & Work environment & $2.6 \pm 0.8$ & $2.7 \pm 0.8$ & -0.428 & -0.08 \\
\hline & & Job fit & $2.1 \pm 0.3$ & $2.0 \pm 0.5$ & -1.633 & -0.30 \\
\hline & & Job motivation & $1.9 \pm 0.6$ & $2.0 \pm 0.4$ & -1.000 & -0.18 \\
\hline \multicolumn{7}{|c|}{ Cooping } \\
\hline & \multirow{6}{*}{$\begin{array}{l}\text { BSCP }+ \\
\text { (Brief Scales for } \\
\text { Coping Profile) }\end{array}$} & Active solution & $5.7 \pm 1.4$ & $5.2 \pm 1.4$ & -1.651 & -0.30 \\
\hline & & Seeking help for solution & $6.2 \pm 1.6$ & $6.0 \pm 1.6$ & -1.052 & -0.12 \\
\hline & & Changing mood & $5.5 \pm 1.5$ & $5.2 \pm 1.6$ & -1.100 & -0.20 \\
\hline & & Taking out emotions to others & $8.9 \pm 2.0$ & $8.7 \pm 1.8$ & -0.880 & -0.16 \\
\hline & & Avoidance and suppression & $7.8 \pm 2.0$ & $7.6 \pm 2.1$ & -0.927 & -0.17 \\
\hline & & Changing a point of view & $7.2 \pm 1.3$ & $6.7 \pm 1.4$ & $-2.215^{*}$ & -0.41 \\
\hline
\end{tabular}

*: $P<0.05, * *: P<0.01, * * *: P<0.001$.

$\dagger$ Always keep in mind and use (1 pt), sometimes use ( 2 pts), almost never use (3 pts), Never use (4 pts).

$\S \quad$ Don't do (1 pt), rarely do (2 pts), sometimes do (3 pts), frequently do (4 pts), always do (5 pts).

$\$$ Always the case (1 pt), sometimes the case (2 pts), almost never the case ( 3 pts), Never the case (4 pts). 
Table 2 Post-program correlations for the recognition group $(n=30)$.

\begin{tabular}{|c|c|c|c|c|c|c|c|c|c|}
\hline Item & $\begin{array}{l}\text { Exploratory } \\
\text { understanding }\end{array}$ & $\begin{array}{l}\text { Surface } \\
\text { adjustment }\end{array}$ & $\begin{array}{l}\text { Suppressed } \\
\text { expression }\end{array}$ & $\begin{array}{l}\text { Expression } \\
\text { of caring }\end{array}$ & $\begin{array}{l}\text { Deep } \\
\text { adjustment }\end{array}$ & $\begin{array}{l}\text { Positive } \\
\text { psychological } \\
\text { response }\end{array}$ & $\begin{array}{l}\text { Negative } \\
\text { psychological } \\
\text { response }\end{array}$ & $\begin{array}{l}\text { Low } \\
\text { back } \\
\text { pain }\end{array}$ & $\begin{array}{l}\text { Physical } \\
\text { complaint }\end{array}$ \\
\hline $\begin{array}{l}\text { Use of body } \\
\text { mechanics } \\
\text { techniques }\end{array}$ & -0.205 & -0.059 & -0.099 & -0.253 & -0.227 & $0.327^{*}$ & 0.065 & 0.145 & 0.000 \\
\hline $\begin{array}{l}\text { Exploratory } \\
\text { understanding }\end{array}$ & & $0.298^{*}$ & $0.363^{* *}$ & $0.613^{* * * *}$ & $0.637^{* * *}$ & -0.201 & -0.006 & -0.008 & 0.031 \\
\hline $\begin{array}{l}\text { Surface } \\
\text { adjustment }\end{array}$ & & & $0.650^{* * *}$ & $0.541^{* * *}$ & $0.483^{* * *}$ & 0.098 & -0.138 & 0.055 & -0.221 \\
\hline $\begin{array}{l}\text { Suppressed } \\
\text { expression }\end{array}$ & & & & $0.583^{* * *}$ & $0.543^{* * *}$ & -0.082 & -0.059 & 0.181 & $-0.259^{*}$ \\
\hline $\begin{array}{l}\text { Expression of } \\
\text { caring }\end{array}$ & & & & & $0.642^{* * *}$ & -0.240 & 0.079 & 0.027 & 0.044 \\
\hline Deep adjustment & & & & & & -0.151 & -0.146 & 0.015 & -0.130 \\
\hline $\begin{array}{l}\text { Positive } \\
\text { psychological } \\
\text { response }\end{array}$ & & & & & & & $-0.448^{* * *}$ & 0.108 & -0.246 \\
\hline $\begin{array}{l}\text { Negative } \\
\text { psychological } \\
\text { response }\end{array}$ & & & & & & & & -0.139 & $0.529^{* * * *}$ \\
\hline Low back pain & & & & & & & & & $-0.474^{* * *}$ \\
\hline
\end{tabular}

*: $P<0.05, * *: P<0.01, * * *: P<0.001$.

order of frequency: "respond out of consideration for myself" (35.3\%), "learn from my mistakes" (29.4\%), "interpret things positively" (23.5\%), "resolve it over time," and "none" (5.9\%).

In contrast, only four categories emerged at post-program: "learn from my mistakes" (40.7\%), "interpret things positively" (25.9\%), "respond out of consideration for myself" (18.5\%), and "role" $(14.8 \%)$.

For the non-recognition group, four pre-program categories emerged: "interpret things positively" (37.5\%), "learn from my mistakes" (25.0\%), "role" (25.0\%), and "respond out of consideration for myself" $(12.5 \%)$. By post-program, five categories emerged: "interpret things positively" (39.1\%), "respond out of consideration for myself" (30.4\%), "learn from my mistakes" (17.4\%), "role" (8.7\%), and "not worried about it" (4.3\%).

\subsection{Between-Groups Comparison of Differences in VAS Results}

For the recognition group, the mean $(S D)$ difference in LBP severity between pre- and post-program was $-3.57(14.0) \mathrm{mm}$. This was significantly lower than the
$5.23(14.9) \mathrm{mm}$ of the non-recognition group $(P=$ $0.034)$.

\subsection{Post-Program Correlations for the Recognition Group}

In the recognition group, the "physical complaints" factor of "physical reactions" was significantly correlated with the "negative psychological responses" item of "psychological reactions" $(r=0.529, P<0.001)$ and the "suppressed expression" factor $(r=-0.259, P=$ 0.046; Table 2) of "behavior." Furthermore, the "use of body mechanics techniques" factor of "behavior" was significantly correlated with the "positive psychological response" item of "psychological reactions" $(r=0.327, P=0.011)$.

\section{Discussion}

Our results showed that by completing this program, some of the nurses better understood that LBP is a biopsychosocial pain syndrome, having demonstrated recognition of the links between LBP and various physical and psychosocial factors. Furthermore, they clearly modified their behavior as part of efforts to improve their LBP. More specifically, our results 
demonstrate the following points concerning the use of cognitive and behavioral modification to improve LBP.

\subsection{Recognition of Physical/Psychosocial Factors}

Before the program, nurses with LBP had a poor recognition of psychosocial factors, but a good recognition of physical factors. This may have been the result of the historical use of the biological injury model in nursing education to explain LBP. After the program, we observed a significant increase in nurses' cognitive recognition of both the physical and psychosocial factors. Cognitive recognition is the understanding derived from knowledge and memories acquired about a subject. Although past knowledge about LBP, subsequent experience, and nursing training may have led nurses to develop a deeply entrenched perception of LBP as a biomedical model, our findings showed that roughly half of the nurses might have been unable to "unlearn" this perception through our program.

\subsection{Behavior Modification in the Recognition Group}

Post-program, the recognition group experienced greater alleviation of LBP than did the non-recognition group. Several factors may have related to this improvement. First, deeply entrenched perceptions derived from nurses' educational backgrounds may have facilitated LBP-related behavior modification, as shown by the increase in behaviors related to improving physical factors, such as the use of body mechanics techniques.

Among psychosocial factors, there was a significant increase in scores on the "changing a point of view" factor of the Brief Scales for Coping Profiles. This is possibly the result of attempts by the person to erase deep-seated feelings through cognitive manipulation, which is a cognitive coping strategy. It may also correspond to emotion-focused coping. Emotion-focused coping has been found to alleviate stress responses to job stress, in much the same way as problem-focused coping; however, such problem-focused coping comes with the possible cost of increased feelings of work overload [31], thus increasing the stress response slightly. Although problem-focused coping aims to directly address stressors, it may lead individuals to feel unnecessarily overburdened when problems have no immediate solution or when issues require an organizational solution. For the recognition group, having cognitive recognition of the psychosocial factors may have increased the use of emotion-focused coping strategies to mitigate stress responses, rather than personally attempting to resolve job stressors. Such a behavioral change may have alleviated the stress response related to LBP, which in turn could have contributed to LBP improvement.

We also observed a significant increase in the "deep adjustment" factor of the Emotional Labor Inventory for Nurses. This refers to the strategy of modifying one's inner, felt emotions in order to express the appropriate emotions (called "deep acting") rather than merely changing the surface-level appearance of emotions ("surface acting") [18]. Deep acting refers to the state of "not deceiving the patient but deceiving oneself," as nurses attempt to modify themselves to feel the emotions that they believe they should [19]. The deep adjustment factor of the Emotional Labor Inventory for Nurses is defined as "the act of a nurse recognizing her own emotional state and generating appropriate emotions," or how they actively adjust their emotions in order to express their feelings in a heartfelt way that can still satisfy their own needs [28]. While similar to deep acting, deep adjustment does not require "self-deception"; instead, it is the act of expressing appropriate emotions by changing the inner emotions (which requires emotional labor) in a way that still feels comfortable. The outcomes of deep acting (e.g., guilt) will differ depending on how one re-evaluates a given situation [32]. In the present study, as nurses with LBP interacted with patients, they may have been able to appropriately re-evaluate the situation at that time to reduce their emotional labor. 
Such an interpretation was supported in this study by participants' responses in the CBT column template. Specifically, participants did not rely solely on others to find ways of thinking more positively, such as "resolving problems over time" or "interpreting things more positively." They also referred to an orientation toward insight, such as being conscious of one's role. Some nurses in this study may have increased their capacity for deep adjustment - and thus remained more comfortable with themselves in modifying their emotions-by fostering an orientation toward replacing negative thinking about situations with more positive thinking.

Cognitive restructuring is a CBT technique for which introspection is essential [20]. It is reasonable to assume that use of the CBT column technique enabled nurses to visualize psychosocial factors introspectively and transform negative thinking patterns into more positive ones. Viewing situations in a more positive light likely contributed to behavior modification.

This study showed that when nurses used this program and learned to recognize the relationship between LBP and physical and psychosocial factors, they were able to modify their behavior. By structuring the program as two modules (knowledge and practice), the nurses came to understand that LBP is a biopsychosocial pain syndrome, which may have facilitated their engaging in behaviors that improve the physical and psychosocial factors related to LBP. LBP is a physical reaction that is influenced by both cognition and behavior, which themselves interact in a circular manner. This was similarly found in the correlations of "physical reactions" with "psychological reactions" and "behavior." This shows the importance of incorporating cognitive factors into LBP education programs as a means of improving LBP among female nurses.

\subsection{Limitations}

LBP is too complex and diverse a concept to capture. Therefore, we must analyze the background of LBP in greater detail. Additionally, in order to avoid introducing confounding factors, we limited potential survey participants to female nurses with specific years of work experience, and recruited participants from multiple facilities. However, less than $30 \%$ of the initial candidates completed the survey. Further studies are needed to increase the validity by increasing the number of participants and by studying the program's effects longitudinally. As alexithymia isn't necessarily a clinical factor, exclusion of those who have received treatment isn't necessarily going to remove this bias.

\section{Conclusion}

Although female nurses are aware of the physical factors for LBP, their recognition of psychosocial factors was relatively low. By recognizing both factors, female nurses can engage in behavioral changes that lead to reduced LBP.

\section{Acknowledgments}

We express our deepest gratitude to the nurses who generously cooperated with this survey.

\section{References}

[1] Ministry of Health, Labour and Welfare. 2013. Guidelines for the Prevention of Low Back Pain in the Workplace. Accessed February 20, 2014. http://www.mhlw.go.jp/stf/houdou/2r98520000034et4-att /2r98520000034mtc_1.pdf

[2] Itoh, H., Kitamura, F., and Yokoyama, K. 2013. "Estimates of Annual Medical Costs of work-Related Low Back Pain in Japan.” An International Scientific Journal of Occupational Health and Safety 51 (5): 524-9.

[3] Sadosky, A. B., Bonaventura, M., Cappelleri, J. C., Ebata, N., and Fujii, K. 2015. "The Association between Lower Back Pain and Health Status, Work Productivity, and Health Care Resource Use in Japan." Journal of Pain Research 8 (1): 119-30.

[4] Hagiwara, T. 2011. "A Consideration for Improving Subjective Low Back Pain in Nurses: Knowing the Relationships between Preparatory Actions and Subjective Low Back Pain.” Nihon Kango Gakkai Ronbunshū, Kango Sōgō 41: 369-70.

[5] Sato, M., Ryuki, S., Baba, T., Sumida, H., Okamura, H., and Shimizu, K. 2008. "Evaluation of Occupational Low Back Pain among Hospital Workers Using Roland-Morris 
Disability Questionnaire." The Central Japan Journal of Orthopaedic Surgery and Traumatology 51 (2): 207-8.

[6] Bono, K., Kubo, C., Ozaki, K., Goto, K., and Tajima, N. 2007. "Risk Factor on Low Back Pain in the Nurses and Care Workers." The Journal of Japanese Society of Lumbar Spine Disorders 13 (1): 113-20.

[7] Kondo, Y., Moriyama, M., Umezawa, Y., Koyama, H., Kawakami, H., Yamagami, Y., and Fujita, M. 2006. "A Survey of Low Back Pain in Ward Nurses As Tsubame Rōsai Hospital." Journal of Occupational Health 48 (6): 228.

[8] Kimura, Y., Fukushima, S., Amada, E., Kanogawa, M., Watanabe, S., and Tashiro, T. 2006. "A Survey of Low Back Pain in Nursing Personnel." Kōtsū Igaku 60 (1-2): 67.

[9] Kiguchi, D., Tauchi, H., Suto, T., Yoshino, K., Katagi, Y., Watanabe, Y., and Kadota, S. 2007. "A Survey of Low Back Pain in an Acute Care Hospital: A Comparison of Nurses and Administrators." Ehime Journal of Medicine 42 (1): 26-7.

[10] Kida, A., Nogutu, S., and Fujiwara, M. 2004. "Survey on Awareness of the Body Mechanics and Low Back Pain in the Ward Nurses". Journal of Fukushima Rosai Hospital 7 (1): 54-8.

[11] Itami, K., Yasuda, T., Otsuki, Y., Ishibashi, M., and Maesako, T. 2009. "Development of Body Mechanics Check System that Focuses on Anteversion Angle in the Action of Beds." Japanese Journal of Educational Technology Research 33 (1): 1-9.

[12] Royal College of General Practitioners 1996. "Clinical Guidelines for the Management of Acute Low Back Pain.” Accessed October 3, 2011. http://www.chiro.org/LINKS/GUIDELINES/FULL/Roya 1_College/

[13] Japanese Orthopaedic Association. 2012. Japanese Society of Lumbar Spine Disorders 2012 Guidelines for the Diagnosis and Treatment of Low Back Pain. Tokyo: Nankodo.

[14] Weiss, J., Quante, S., Xue, F., Muche, R., and Reuss-Borst, M. 2013. "Effectiveness and Acceptance of Acupuncture in Patients with Chronic Low Back Pain: Results of a Prospective, Randomized, Controlled Trial.” Alternative and Complementary Medicine 19 (12): 935-41.

[15] Cho, H.-Y., Kim, E.-H., and Kim, J. 2014. "Effects of the CORE Exercise Program on Pain and Active Range of Motion in Patients with Chronic Low Back Pain." Journal of Physical Therapy Science 26 (8): 1237-40.

[16] Méndez, F. J., and Gómez-Conesa, A. 2001. "Postural Hygiene Program to Prevent Low Back Pain." Spine 26 (11): 1280-6.

[17] Ministry of Health, Labour and Welfare. 2010. "Comprehensive Survey of Living Conditions, 2010."
Accessed May $\quad 2012$. http://www.mhlw.go.jp/toukei/saikin/hw/k-tyosa/k-tyosa1 0/3-1.html

[18] Takei, A. 2001. Emotions and Nursing: The Meaning of Making a Profession of Relating to People. Tokyo: Igaku-shoin.

[19] Hochschild, A. R. 2000. The Managed Heart. Translated by Ishikawa, J., and Murofushi, A. Kyoto: Sekaishisosha.

[20] Ito, E. 2011. An Introduction for Caregivers to Cognitive Behavioral Therapy for Simplifying Self-care, Book 1. Tokyo: Igaku-shoin.

[21] Takeda, K., and Watanabe, Y. 2012a. "Physical Posture, Psychological Attitude, and Social Attitude Characteristics at Year 1 and Year 5 of University Graduate Nurses with Low Back Pain.” Japanese Journal of Nursing Research 35 (3): 278.

[22] Takeda, K., and Watanabe, Y. 2012b. "Factors Related to Low Back Pain, Physical Posture, Psychological Attitude, and Social Attitude in Female Nurses." Japanese Journal of Nursing Research 35 (2): 113-22.

[23] Takeda, K., Watanabe, Y., and Harada, T. 2016, "Relationship between Low Back Strain While Assisting with Wheelchair Transfer and Frontal Cognitive Function Using the Go/No - Go Task." The Journal of Health Sciences, Nihon Fukushi University 19: 11-8.

[24] Watarai, K. 2009. Standing Beautifully: 3 A's to Be Learned from Sports Medicine. Tokyo: Bunkodo.

[25] Konno, S. I. 2011. "Dopamine System and Pain." The Japan Journal of Clinical Orthopaedic Association 46 (4): 343-6.

[26] Shioiri, T. 2012. "Three Questions for Diagnosing Whether the CBT Column Technique Can Be Used to Treat Insomnia due to Amygdalar Panic Disorder in Order to Sleep Well." Accessed June 20, 2012. http://topicsnow.blog72.fc2.com/blog-entry-4389.html

[27] Ministry of Health, Labor and Welfare. 2003. "Report of the Fifth Investigative Commission on Skills Training in Basic Nursing Education.” Accessed May 7, 2012. http://www.mhlw.go.jp/shingi/2003/03/s0317-5b.html

[28] Katayama, Y., Ogasawara, C., Tsuji, C., Imura, K., and Nagayama, H. 2005. "Development of Emotional Labor Inventory for Nurses." The Japan Journal of Nursing Science 25 (2): 20-7.

[29] Shimomitsu, T. 2005. "Research on the Improvement of the Workplace Environment for Better Mental Health." Ministry of Education, Science, Sports and Culture.

[30] Kageyama, T., Kobayashi, T., Kawashima, M., and Kanamaru, Y. 2004. "Development of the Brief Scales for Coping Profile (BSCP) for Workers: Basic Information about its Reliability and Validity." Japan Society for Occupational Health 46 (4): 103-14.

[31] Takaya, M., and Hasegawa, Y. 2010. "An Analysis of the 
Relation between Stress Coping Profile and Job Stress Using Structural Equation Modeling (SEM)." Journal of Occupational Health 52 (5): 209-15.

[32] Sakakibara, R. 2011. "A Review of Studies of Emotional
Labor and the Reconsideration of the Conceptualization and Suggesting the New Perspective." Bulletin of the Graduate School of Education, the University of Tokyo 51: 175-82. 